\title{
HUBUNGAN MENYUSUI EKSKLUSIF DENGAN INVOLUSI UTERI PADA IBU POSTPARTUM DI KOTA BANDAR LAMPUNG
}

\author{
Uli Marati*, Nyimas Aziza* \\ *Jurusan Kebidanan Poltekkes Tanjungkarang
}

\begin{abstract}
Kecepatan involusi uteri di pengaruhi oleh beberapa faktor, antara lain usia ibu, jumlah anak yang dilahirkan (paritas), menyusui eksklusif, mobilisasi dini, dan menyusui dini. Efek samping produksi air susu ibu dapat memperbaiki involusi uterus. Jenis penelitian ini adalah analitik dengan pendekatan cross sectional. Populasi pada penelitian ini adalah pasien post partum spontan yang berjumlah 40 orang. Sampel yang digunakan dalam penelitian ini adalah total populasi, sebanyak 40 orang. Hasil penelitian didapatkan bahwa Sebagian besar responden menyusui secara eksklusif yaitu sebanyak 34 orang $(87,5$ $\%)$. Sebagian besar responden mengalami involusi uteri dalam katagori baik yaitu sebanyak 34 orang (85\%). Ada hubunganyang antara menyusui eksklusif dengan involusi uteri dengan p value 0,008 dan OR 33, 000. Peneliti menyarankan agar dapat meningkatkan mutu dan kualitas pelayanan kesehatan dengan lebih menekankan pelaksanaan menyusui eksklusif pada ibu postpartum dan dapat digunakan sebagai prosedur tetap dalam pelayanan post partum sehingga dapat mengurangi angka kematian pada ibu.
\end{abstract}

\section{Kata kunci: Menyusui ekslusif, Involusi Uterus, Post Partum}

\section{LATAR BELAKANG}

Keberhasilan upaya kesehatan ibu, di antaranya dapat dilihat dari indikator Angka Kematian Ibu (AKI). Penurunan AKI di Indonesia terjadi sejak tahun 1991 sampai dengan 2007, yaitu dari 390 menjadi 228. Namun demikian, SDKI tahun 2012 menunjukkan peningkatan AKI yang signifikan yaitu menjadi 359 kematian ibu per 100.000 kelahiran hidup. AKI kembali menujukkan penurunan menjadi 305 kematian ibu per 100.000 kelahiran hidup berdasarkan hasil Survei Penduduk Antar Sensus (SUPAS) 2015. Lima penyebab kematian ibu terbesar yaitu perdarahan, hipertensi dalam kehamilan (HDK), infeksi, partus lama/macet, dan abortus. Kematian ibu di Indonesia masih didominasi oleh tiga penyebab utama kematian yaitu perdarahan, hipertensi dalam kehamilan (HDK),dan infeksi (Kemenkes RI, 2015)

AKI di provinsi lampung masih cukup tinggi, Berdasarkan Survey Demografi Kesehatan Indonesia (SDKI) Angka Kematian Ibu (AKI) selama tahun1997 - 2012 cenderung meningkat kembali dimana dari 370 per 100.000 kelahiran hidup menjadi 359 per 100.000 kelahiran hidup tahun 2012 (target 102 per 100.000 kelahiran hidup). Penyebab kasus kematian ibu di Provinsi lampung tahun 2013 disebabkan oleh perdarahan sebanyak 47 kasus, eklamsi sebanyak 46 kasus, infeksi sebanyak 9 kasus, partus lama sebanyak 1 kasus, aborsi sebanyak 1 kasus dan lain-lain sebanyak 54 kasus. (Dinas Kesehatan Lampung, 2014)

Masa puerperium atau masa nifas mulai setelah partus selesai, dan berakhir setelah kira-kira 6 minggu. Akan tetapi, seluruh alat genital baru pulih kembali seperti sebelum ada kehamilan dalam waktu 3 bulan. Dalam masa nifas, alat-alat genetalia interna maupun eksterna akan berangsur-angsur pulih kembali seperti keadaan sebelum hamil. Perubahanperubahan alat-alat genital ini dalam keseluruhannya disebut involusi. Di samping involusi terjadi juga perubahanperubahan penting lain, yakni hemokonsentrasi dan timbulnya laktasi. Yang terakhir ini karena pengaruh Lactogenetic Hormon dari kelenjar hipofisi terhadap kelnjar-kelenjar mammae (Prawirohardjo, 2007) 
Kecepatan involusi uteri di pengaruhi oleh beberapa faktor, antara lain usia ibu, jumlah anak yang dilahirkan (paritas), menyusui eksklusif, mobilisasi dini, dan menyusui dini. Proses menyusui membantu mempercepat pengembalian rahim kebentuk semula dan mengurangi perdarahan. Hal ini disebabkan adanya isapan bayi pada payudara dilanjutkan melalui saraf ke kelenjar hipofise di otak yang mengeluarkan hormon oksitosin. Oksitosin selain bekerja untuk mengkontraksi saluran ASI pada kelenjar air susu juga merangsang uterus untuk berkontraksi sehingga mempercepat involusio uteri (Depkes RI, 2008).

Rangsangan psikis merupakan refleks dari mata ibu ke otak, mengakibatkan oksitosin dihasilkan, sehingga air susu ibu dapat dikeluarkan dan pula sebagai efek sampingan memperbaiki involusi uterus (Prawirohardjo, 2007). Faktor yang mempengaruhi involusi uterus antara lain : mobilisasi dini, status gizi, menyusui, usia dan paritas (Prawirohardjo, 2002).

Dalam waktu 12 jam, tinggi fundus uteri mencapai kurang lebih $1 \mathrm{~cm}$ di atas um umbilikus. Dalam beberapa hari kemudian, perubahan involusi berlangsung dengan cepat. Fundus turun kira-kira 1-2 cm setiap 24 jam (Dewi, 2011)

Berdasarkan hasil penelitian Friske Wulan, Siti Fatonah dengan judul Pengaruh Menyusui Terhadap Penurunan Tinggi Fundus Uteri Pada Ibu Postpartum Primigravida di RSUD Dr. R. Sosodoro Djatikoesoemo Bojonegoro dengan hasil tabulasi silang didapatkan bahwa ada pengaruh menyusui terhadap penurunan tinggi fundus uteri pada ibu post partum primigravida yaitu dari 8 responden $(50 \%)$ ibu post partum yang menyusui dengan baik terdapat 7 responden $(43,75 \%)$ yang penurunan tinggi fundus uterinya normal. Disimpulkan ada pengaruh menyusui terhadap penurunan Tinggi Fundus Uteri pada ibu post partum primigravida.

Berdasarkan hasil pra survey di salah satu BPM swasta didapatkan data peningkatan kejadian perdarahan. pada tahun 2015 terdapatkan 1,73\% kejadian perdarahan post partum dari sekitar 576 ibu post partum dan pada tahun 2016 didapatkan 2,19\% kejadian perdarahan post partum dari sekitar 592 ibu post partum. Dan pada involusi uteri tahun 2015 terdapat $2,77 \%$ penurunan TFU yang tidak sesuai, sedangkan pada tahun 2016 terdapat $3,37 \%$ penurunan TFU yang tidak sesuai.

Berdasarkan hasil survey didapatkan 2 dari 5 ibu post partum yang mengalami involusi yang kurang sesuai dan berdasarkan hasil wawancara di dapatkan bahwa ibu post partum masih tidak mau menyusui bayi nya dengan alasan ibu masih merasa lemas setelah melahirkan dan air susu ibu belum keluar. Berdasarkan teori yang ada bahwa menyusui atau isapan bayi dapat menghasilkan hormon oksitosin sehingga dapat membantu dalam involusi uteri ibu sehingga mencegah terjadi nya perdarahan post partum.

\section{METODE}

Desain penelitian ini adalah analitik yang bertujuan unutuk mencari hubungan antar variabel. Rancangan penelitian ini menggunakan pendekatan cross sectional yaitu penelitian untuk mempelajari dinamika korelasi antara faktor resiko dengan efek, dengan cara pendekatan observasi atau pengumpulan data sekaligus satu waktu (point time approach). Populasi pada penelitian ini adalah pasien post partum spontan yang berjumlah 40 orang. Sampel yang digunakan dalam penelitian ini adalah total populasi, sebanyak 40 orang.

Data dikumpulkan melalui observasi dan wawancara terhadap variabel ASI eksklusif dan involusi fundus uteri. Selanjutnya data diolah dengan menngunakan uji chi square. 
HASIL

\section{Karakteristik Responden}

Responden dalam penelitian ini sejumlah 40 orang denga karakteristik lebih dari separuh berusia antara 20-30 tahun $(67,5 \%)$ dan lebih dari separuh mempunyai usia 20-30 tahun yaitu 27 $(67,5 \%)$ orang.

\section{Analisis Univariat}

Tabel 1: Distribusi Frekuensi Menyusui Eksklusif pada Ibu Post Partum

\begin{tabular}{rcc}
\hline Menyusui & $\mathrm{f}$ & $\%$ \\
\hline Eksklusif & 34 & 87.5 \\
\hline Tidak Eksklusif & 6 & 12.5 \\
\hline Jumlah & 40 & 100 \\
\hline
\end{tabular}

Berdasarkan tabel di atas dapat dilihat bahwa sebagian besar responden menyusui secara eksklusif yaitu sebanyak 34 orang $(87,5 \%)$.

Tabel 2: Distribusi Frekuensi Involusi Uteri pada Ibu Post Partum

\begin{tabular}{lccc}
\hline \multicolumn{2}{c}{ Kontraksi Uterus } & f & $\%$ \\
\hline Baik & 34 & 85.0 \\
\hline Buruk & 6 & 15.0 \\
\hline \multicolumn{2}{c}{ Jumlah } & 40 & 100 \\
\hline
\end{tabular}

Berdasarkan tabel di atas dapat dilihat bahwa sebagian besar responden mengalami involusi uteri dalam katagori baik yaitu sebanyak 34 orang (85\%).

\section{Analisis Bivariat}

Tabel 3: Hubungan Menyusui Eksklusif dengan Involusi Utreri pada Ibu Post Partum

\begin{tabular}{lcccccc}
\hline \multirow{2}{*}{ Menyusui } & \multicolumn{3}{c}{ Kontraksi Uteri } & \multicolumn{2}{c}{ Total } \\
\cline { 2 - 7 } & \multicolumn{2}{c}{ Baik } & \multicolumn{3}{c}{ Buruk } \\
\cline { 2 - 7 } & $\mathrm{f}$ & $\%$ & $\mathrm{f}$ & $\%$ & $\mathrm{f}$ & $\%$ \\
\hline Eksklusif & 33 & 91.7 & 1 & 2.9 & 34 & 100 \\
\hline Tidak Eksklusif & 1 & 16.7 & 5 & 83.3 & 6 & 100 \\
\hline Jumlah & 34 & 85.0 & 6 & 15.0 & 40 & 100 \\
\hline$p$ value & \multicolumn{5}{c}{0,008} \\
\hline OR & \multicolumn{6}{c}{33,000} \\
\hline
\end{tabular}

Berdasarkan tabel di atas dapat diketahui bahwa responden yang melakukan menyusui eksklusif dengan involusi uteri baik sebesar 33orang (91.7\%) dan 5orang (83.3\%) responden yang tidak melakukan menyusui eksklusif dengan kontraksi uterus buruk. Hasil uji statistic $p$ value berarti $p$ value $\leq \alpha$ maka Ha diterima dan Ho ditolak berarti ada hubungan yang antara menyusui eksklusif dengan involusi uteri pada ibu post partum. Didapatkan nilai nilai $p$ value $=$ 0,008 dan nilai $\mathrm{OR}=33.000$ artinya ibu yang melaksanakan menyusui eksklusif mempunyai peluang33.000kali mengalami kontraksi uterus baik dibandingkan ibu yang tidak melaksanakan menyusui eksklusif.

Dikarenakan menyusui eklsklusif tidak hanya bermanfaat bagi bayi, tapi bermanfaat juga bagi ibu dikarenakan menyusui eksklusif dapat membantu pengembalian involusi uteri secara baik. Maka di butuhkan peran serta tenaga kesehatan khusus nya bidan untuk selalu melakukan promosi dan pelayanan tentang menyusui secara eksklusif, sehingga di harapkan dapat mengurangi angka kematian ibu dikarenakan perdarahan 


\section{PEMBAHASAN}

\section{Menyusui eksklusif pada Ibu Post Partum}

Dari hasil penelitian tentang hubungan menyusui dengan involusi uteri pada ibu postpartum yang terkaji dalam tabel distribusi frekuensi pelaksanaan menyusui eksklusif, didapatkan $85.0 \%$ (34 orang) melakukan menyusui eksklusif selama 2 hari dan $15.0 \%$ (6 orang) yang tidak melakukan menyusui secara eksklusif.Diharapkan dari menyusui eklsklusif tidak hanya bermanfaat bagi bayi tapi bagi ibu dikarenakan menyusui eksklusif dapat membantu pengembalian involusi uteri kembali seperti semula sehingga di harapkan dapat mengurangi angka kematian ibu dikarenakan perdarahan.

Hal ini sejalan dengan teori yang ada bahwa manfaat pemberian ASI membantu ibu memulihkan diri dari proses persalinannya, Pemberian ASI selama beberapa hari pertama membuat rahim berkontraklsi dengan cepat dan memperlambat perdarahan (hisapan pada putting susu merangsang dikeluarkannya oksitosin alami yang akan membantu kontraksi rahim). Pemberian ASI adalah cara yang penting bagi ibu untuk mencurahkan kasih sayangnya pada bayi dan membuat bayi merasa nyaman (Suherni, 2009).Pada proses menyusui ada reflek let down dari isapan bayi merangsang hipofise posterior mengeluarkan hormon oktosin yang oleh darah hormon ini diangkat menuju uterus dan membantu uterus berkontraksi sehingga proses involusi uterus terjadi (Prawirohardjo, 2002).

Hal ini didukung oleh penelitian yang dilakukan oleh Friske Wulan, Siti Fatonah dengan judul penelitian Pengaruh Menyusui Terhadap Penurunan Tinggi Fundusuteri Pada Ibu Post Partum Primigravidadi RSUD Dr. R. Sosodoro Djati Koesoemo Bojonegoro menunjukkan data bahwa salah satu keuntungan dari menyusui bagi ibu menyebabkan uterus berkontraksi sehinggapengembalian uterus ke keadaan fisiologis lebih cepat, namun menyusui itu sendiri jugadipengaruhi oleh beberapa faktor. Salah satu faktor yang mempengaruhi adalah pekerjaan,ibuyang bekerja tidak bisa memberikan ASI secara eksklusif sehingga akan mempengaruhi sekresi hormon dan produksi ASI, sehingga pelaksanaan menyusui di lakukan kurang maksimal. Daripenelitian ini sebanyak 13 orang $(81,30 \%)$ bekerja sebagai ibu rumah tangga sehinggapelaksanaan menyusui bisa dilakukan dengan maksimal.

Berdasarkan teori dan hasil penelitian diatas, menurut peneliti cakupan menyusui eksklusif di BPM Kartini Kebon Jeruk Bandar Lampung cukup baik, karena sebagian responden menyusui secara eksklusif. Dengan demikian manfaat menyusui eksklusif sangat besar baik bagi ibu ataupun bayinya. Oleh karena itu perlu adanya dukungan dari keluarga serta penyuluhan dari petugas kesehatan khususnya bidan, sehingga kualitas pelayanan terhadap ibu dan bayi tetap optimal, penelitian ini juga dapat meningkatkan kesadaran dan memotivasi responden untuk melaksanakan menyusui eksklusif. Dengan demikian peniliti berharap pelayanan bagi ibu postpartum khusus nya menyusui eksklusif adalah menjadi salah satu prioritas yang di terapkan di pelayanan kesehatan BPM Kartini Kebon Jeruk Bandar Lampung.

\section{Involusi Uteri pada Ibu Post Partum}

Dari hasil penelitian menunjukkan bahwa gambaran involusi uteri pada ibu post partum yang didapatkan datadistribusi frekuensi kontraksi uteri pada ibu post partum menunjukkan bahwa ibu postpartum dengan kontraksi uteri baik didapatkan $85.0 \%$ (34 orang) dan kontraksi uterus yang buruk sebanyak $15.0 \%$ (6 orang). Kontraksi buruk pada ibu yang melakukan menyusui juga dipengaruhi frekuensi ibu menyusui yang belum terlalu sering serta ASI yang tidak lancar dan terdapat ibu yang putting nya masuk kedalam. Salah satu faktor yang mempengaruhi pengembalian ukuran 
uterus adalah hormon oksitosin yang dapat dihasilkan dengan cara menyusui.

Hal ini sejalan dengan teori, Oksitosin menyebabkan terjadinya kontraksi dan retraksi otot uteri sehingga akan menekan pembuluh darah yang mengakibatkan berkurangnya suplai darah ke uterus. Proses ini membantu untuk mengurangi situs atau tempat implantasi plasenta serta mengurangi perdarahan. Penurunan ukuran uterus yang cepat itu dicerminkan oleh perubahan lokasi uterus ketika turun keluar dari abdomen dan kembali menjadi organ pelvis.(Dewi, 2011). Pada wanita yang memilih menyusi bayinya, isapan sang bayi akan merangsang keluarnya oksitosin lagi dan ini membantu uterus kembali ke bentuk normal dan pengeluaran air susu. (Ambarwati, 2009).

Sejalan dengan teori diatas, peneliti menyimpulkan bahwa oksitosin memengaruhi jaringan otot polos rahim dan membantu mengurangi terjadinya perdarahan. Oleh karena itu, ibu harus menyusui secara eksklusif $0-6$ bulan. Dengan seringnya menyusui maka kontraksi uteri semakin baik sehingga memengaruhi proses involusi uteri yaitu kembalinya rahim ke ukuran semula.

\section{Hubungan Menyusui Eksklusif dengan Involusi Utrei Pada Ibu Post Partum}

Berdasarkan hasil penelitian dari 34 orang responden yang melaksanakan menyusui eksklusif ada 1 orang (2.9\%) dengan kontraksi uteri buruk sedangkan dari 6 responden yang tidak melakukan menyusui ekskklusif ada 1 orang (16.7\%) yang mengalami kontraksi uteri baik. Kontraksi uteri ibu buruk dikarena frekuensi ibu menyusui yang belum terlalu sering serta ASI yang tidak lancar dan terdapat ibu yang puting nya tidak menonjol (masuk kedalam).

Hal ini sejalan dengan teori, Kontraksi dan retraksi otot uterin akan mengurangi perdarahan. selama tahap ketiga persalinan, oksitosin menyebabkan pemisahan plasenta. Kemudian seterusnya bertindak atas otot yang menahan kontraksi, melepaskan plasenta dan mencegah perdarahan. pada wanita yang memilih menyusi bayinya, isapan sang bayi akan merangsang keluarnya oksitosin lagi dan ini membantu uterus kembali ke bentuk normal dan pengeluaran air susu. (Ambarwati, 2009).

Hasil penelitian ini sesuai dengan penelitian yang dilakukan oleh Nulailis Saadah dengan judul 'Hubungan Pemberian ASI pertama dengan involusi uterus ibu post partum normal hari ke 7 di BPS Sri Widajati Kawedanan pada bulan Mei - Juni 2008. Populasi penelitian adalah ibu pospartum normal pada hari ke7 sebanyak 32 orang yang kesemuanya dijadikan subyek penelitian. Berdasarkan data yang diperoleh dari 32 responden didapatkan hasil ibu yang memberikan ASI pertama secara dini sebanyak 25 orang $(78,1 \%)$ dan ibu yang memberikan ASI pertama secara tidak dini sebanyak 7 orang $(21,9 \%)$. Analisis secara deskriptif menunjukkan bahwa ibu yang memberikan ASI pertama secara dini seluruhnya (25 orang) memiliki involusi uterus baik. Ibu yang memberikan ASI pertama secara tidak dini, yang memiliki involusi uterus baik sebanyak 2 orang $(28,6 \%)$ dan yang memiliki involusi uterus tidak baik sebanyak 5 orang (71,4\%).Hasil Fisher Exact Test menunjukkan adanya hubungan antara waktu pemberian ASI pertama dengan involusi uterus ibu post partum normal hari ke 7 .

Hasil uji statistik dengan Chi Square dengan $p$ value 0,008 yang berarti terdapat hubungan yang signifikan antara menyusui eksklusif dengan involusi uteri pada ibu postpartum. Didapatkan pula nilai $\mathrm{OR}=$ 33.000 yang artinya ibu yang melakaksanakan menyusui eksklusif mempunyai peluang 33 kali mengalami involusi yang baik dibandingkan ibu yang tidak melaksanakan menyusui eksklusif.

Temuan ini sesuai dengan teori (Varney, 2007) Involusi uterus meliputi reorganisasi dan pengeluaran desisua/endometrium dan eksfoliasi tempat perlekatan plasenta yang di tandai dengan penurunan ukuran dan berat serta perubahan pada lokasi uterus juga ditandai 
dengan warna dan jumlah lokia. Banyaknya lokia dan kecepatan involusi tidak di pengaruhi oleh pemberian rangkaian preparat ergot (Ergotrate, Methergine) yang hanya mempunyai efek jangka pendek. Akan tetapi, menyusi akan mempercepat proses involusi.

Didukung oleh teori Prawirohardjo (2002) Pada proses menyusui ada reflek let down dari isapan bayi merangsang hipofise posterior mengeluarkan hormon oktosin yang oleh darah hormon ini diangkat menuju uterus dan membantu uterus berkontraksi sehingga proses involusi uterus terjadi.

Menurut penliti bahwa dari hasil penelitian Hubungan Menyusui Eksklusif dengan Involusi uteri didapatkan hasil yaitu adanya hubungan menyusui eksklusif dengan involusi uteri pada ibu postpartum karena saat menyusui terjadi kontak kulit ke kulit antara ibu dan bayi yang memberikan ketenangan bagi ibu dan bayi. Hentakan kaki, kepala, jilatan dan isapan bayi membantu merangsang pengeluaran hormon oksitosin secara alamiah sehingga uterus berkontraksi. Keberhasilan ini didukung oleh kondisi ibu dan bayi, serta kesadaran motivasi yang tinggi dari pasien.

Sosialisasi dari tenaga kesehatan tentang menyusui eksklusif hendaknya dilakukan dari Antenatal Care oleh bidan dan semua tenaga kesehatan untuk mendukung dan memotivasi ibu sejak dini serta untuk melakukan pelayanan ibu dan anak yang baik.

\section{KESIMPULAN}

Berdasarkan hasil penelitian dan pembahasan tentang Hubungan Menyusui Eksklusif dengan Involusi Uteri Pada Ibu Postpartum dapat disimpulkan bahwa sebagian besar responden menyusui secara eksklusif yaitu sebanyak 34 orang $(87,5$ $\%$ ) dan sebagian besar mengalami involusi uteri dalam katagori baik yaitu sebanyak 34 orang $(85 \%)$.
Hasil analisis lebih lanjut secara statistik menyimpulkan bahwa ada hubungan yang anatara menyusui eksklusif dengan involusi uteri dengan $p$ value 0,008 dan OR 33, 000.

Berdasarkan hal tersebut penulis menyarankan agar BPM dapat meningkatkan mutu dan kualitas pelayanan kesehatan dengan lebih menekankan pelaksanaan menyusui eksklusif pada ibu postpartum dan dapat digunakan sebagai prosedur tetap bagi BPM sehingga dapat mengurangi angka kematian pada ibu. Selanjutnya bagi bidan dan tenaga kesehatan lainnya agar meningkatkan kualitas pelayanan terutama melakukan program menyusui eksklusif pada ibu postpartum, meningkatkan program promosi kesehatan dengan melakukan penyuluhan dan konseling mengenai pentingnya menyusui eksklusif bagi ibu dan bayi

\section{DAFTAR PUSTAKA}

Ambarwati, R., Wulandari, D. (2009). Asuhan Kebidanan Nifas. Yogyakarta: Mitra Cendika.

Depkes RI. (2008). Profil Kesehatan Indonesia. Jakarta: Kemenkes RI.

Dewi, V.N.L., Sunarsih, T. (2011). Asuhan Kebidanan Ibu Nifas. Jakarta: Salemba Medika.

Dinas Kesehatan Provinsi Lampung. (2015). Profil Kesehatan Provinsi lampung Tahun 2014. Bandar Lampung: Dinkes Provinsi Lampung.

Kemenkes RI. (2015). Profil Kesehatan Indonesia. Jakarta

Prawirohardjo, S. (2002). Ilmu Kandungan. Jakarta: Yayasan Bina Pustaka

(2007). Ilmu

Kebidanan. Jakarta: Yayasan Bina Pustaka

(2008). Ilmu

Kandungan. Jakarta: Yayasan Bina Pustaka 
Suherni, dkk. 2009. Perawatan Masa Nifas. Yogjakarta : Fitramaya
Varney ,H. (2007). Buku Ajar Asuhan Kebidanan. Edisi 4, Volume 2. Jakarta: EGC. 